\title{
Antrodia camphorata Grown on Germinated Brown Rice Suppresses Melanoma Cell Proliferation by Inducing Apoptosis and Cell Differentiation and Tumor Growth
}

\author{
Minjung Song, Dong Ki Park, and Hye-Jin Park \\ Department of Bioscience and Biotechnology, Konkuk University, Gwangjin-gu, Achasan-ro 263, Seoul 143-701, Republic of Korea \\ Correspondence should be addressed to Hye-Jin Park; hyejinp@konkuk.ac.kr
}

Received 26 November 2012; Accepted 16 January 2013

Academic Editor: Senthamil R. Selvan

Copyright (C) 2013 Minjung Song et al. This is an open access article distributed under the Creative Commons Attribution License, which permits unrestricted use, distribution, and reproduction in any medium, provided the original work is properly cited.

\begin{abstract}
Antrodia camphorata grown on germinated brown rice (CBR) was prepared to suppress melanoma development. CBR extracts were divided into hexane, EtOAc, $\mathrm{BuOH}$, and water fractions. Among all the fractions, EtOAc fraction showed the best suppressive effect on B16F10 melanoma cell proliferation by CCK-8 assay. It also showed the increased cell death and the changed cellular morphology after CBR treatment. Annexin V-FITC/PI, flow cytometry, and western blotting were performed to elucidate anticancer activity of CBR. The results showed that CBR induced p53-mediated apoptotic cell death of B16F10. CBR EtOAc treatment increased melanin content and melanogenesis-related proteins of MITF and TRP-1 expressions, which supports its anticancer activity. Its potential as an anticancer agent was further investigated in tumor-xenografted mouse model. In melanoma-xenografted mouse model, melanoma tumor growth was significantly suppressed under CBR EtOAc fraction treatment. HPLC analysis of CBR extract showed peak of adenosine. In conclusion, CBR extracts notably inhibited B16F10 melanoma cell proliferation through the p53mediated apoptosis induction and increased melanogenesis. These findings suggest that CBR EtOAc fraction can act as an effective anticancer agent to treat melanoma.
\end{abstract}

\section{Introduction}

Melanoma is the most serious type of skin cancer, and recently it has become a leading cause of death among the various skin diseases. For example, about 48,000 melanomarelated deaths occur every year on a worldwide basis $[1,2]$. Moreover, the incidence of melanoma has steadily increased in the past few decades [3]. When diagnosed with malignant melanoma, most patients ultimately die of their disease within two years. As a malignant melanoma therapy, standard cancer therapies such as irradiation, chemotherapy, and surgical excision are applied. However, high resistance, limited efficacy, and side effects of current therapeutical methods result in a poor survival rate. Therefore, application of therapeutic agents from natural sources to patients has been attempted as an alternative treatment. Recent reports showed efficacy of several compounds from nutritional sources such as genistein and resveratrol against melanoma [4-6]. In these reports, although they have shown an inhibitory effect against melanoma tumor development and growth, some of them remain as chemoprevention rather than chemotherapy or only focus on in vitro study. Therefore further study is required for improving therapeutic efficiency and applying to the clinics.

Herein, we focused on Changji mushroom (Antrodia camphorata) grown on germinated brown rice (CBR) as an anticancer agent against melanoma. As a traditional oriental medicine, Antrodia camphorata (AC) has been used to treat food and drug detoxification, diarrhea, abdominal pain, and hypertension. Recently, anticancer activities of Antrodia camphorata against human colon and breast cancer cells have been reported [7-9]. In addition, they induced an apoptosis of human ovarian cancer and hepatocellular carcinoma cells $[10,11]$. However, the anticancer activity of Antrodia camphorata on melanoma has not been investigated yet.

In this study, Changji mushroom (Antrodia camphorata) on germinated brown rice $(\mathrm{CBR})$ extracts was prepared. 
Its inhibitory effect against B16F10 melanoma cell proliferation was evaluated. The cause of cancer cell death was further investigated with annexin V-FITC/PI staining, flow cytometry, the measurement of melanin content, and western blot analysis. In addition, CBR extract was administered to melanoma xenografted mice to investigate its inhibitory effect on melanoma growth.

\section{Materials and Methods}

2.1. Cell Culture. B16F10 mouse melanoma cell line was purchased from American Type Culture Collection (Rockville, MD, USA) and cultured in minimum essential media (MEM) (Invitrogen, Carlsbad, CA, USA) supplemented with $10 \%$ fetal bovine serum (FBS) (Invitrogen) and $200 \mathrm{U} / \mathrm{mL}$ penicillin-streptomycin (Sigma, St. Louis, MO, USA). In all experiments, cells were grown to $80 \%-90 \%$ confluence and subjected to no more than 15 passages.

2.2. Preparation of CBR Extract. Antrodia camphorata on germinated brown rice (CBR) was provided by Cell Activation Research Institute (CARI, Seoul, Korea). Authenticated voucher specimens of Antrodia camphorata (AC) (Kucari 1101) and CBR (Kucari 1102) are deposited in the Herbarium at College of Bioscience and Biotechnology, Konkuk University (Seoul, Republic of Korea). AC was inoculated on germinated brown rice and cultured at $20-25^{\circ} \mathrm{C}$ for 4 weeks. Powder was extracted under reflux with $80 \% \mathrm{MeOH}$. The powdered material $(1 \mathrm{~kg})$ was extracted under reflux with $80 \% \mathrm{EtOH}$. The total extract (178 g, yield [w/w], 17.8\%) was dissolved in water. After removing the insoluble solid particles by filtration, the liquid phase was extracted sequentially by solvents with increasing polarity (hexane, EtOAc, $\mathrm{BuOH}$, and water; $1: 10[\mathrm{w} / \mathrm{v}]$ for all solvents) to yield four fractions. The liquidliquid phase extraction was performed in Erlenmeyer flasks by shaking, and the extracts were concentrated to dryness by a rotary evaporator. Thus, we obtained the following fractions: hexane fraction $(16 \mathrm{~g}$, yield $(\mathrm{w} / \mathrm{w}) 1.6 \%)$, EtOAc fraction ( $4.5 \mathrm{~g}$, yield $(\mathrm{w} / \mathrm{w}) 0.45 \%), \mathrm{BuOH}$ fraction $(8.25 \mathrm{~g}$, yield $(\mathrm{w} / \mathrm{w})$ $0.825 \%)$, and water fraction (10.86 g, yield (w/w) $1.086 \%)$.

2.3. Cell Proliferation Assay. Melanoma cell viability in the absence and presence of different concentrations of AC and CBR was measured with CCK-8 assay (Dojindo, Rockville, MD, USA). Briefly, cells were plated onto 96 -well plates $(5 \times$ $10^{3}$ cells/well) and treated with $\operatorname{CBR}(0,1,10$, and $25 \mu \mathrm{g} / \mathrm{mL})$ for 48 and 72 hours. CCK- 8 solutions were added and incubated for 2 hours, followed by viable cell detection with a microplate reader at $450 \mathrm{~nm}$ absorbance (Model 550; BioRad, Hercules, CA, USA).

2.4. Annexin V-FITC/PI Staining. The extent of B16F10 apoptosis by CBR EtOAc fraction was evaluated by annexin $\mathrm{V}$ FITC/PI apoptosis detection kit (Trevigen Inc., Gaithersburg, $\mathrm{MD}$, USA), according to the manufacturer's instructions. B16F10 melanoma cells were incubated in a 6-well plate (3 $\times 10^{5}$ cells/well) and treated with CBR EtOAc fraction at different concentrations $(0,1,5$, and $10 \mu \mathrm{g} / \mathrm{mL})$ for 48 hours.
Cells were harvested and fixed in ice-cold $70 \%$ ethanol at $4^{\circ} \mathrm{C}$ overnight. FACS was used to determine the percentage of cells displaying annexin $\mathrm{V}-\mathrm{FITC}^{+} / \mathrm{PI}^{+}$(necrosis), annexin $\mathrm{V}$ FITC $^{-} / \mathrm{PI}^{+}$(late apoptosis), annexin V-FITC ${ }^{-} / \mathrm{PI}^{-}$(normal), or annexin $\mathrm{V}$-FITC ${ }^{+} / \mathrm{PI}^{-}$staining (early apoptosis). At least 10,000 cells were used for each analysis, and experiments were performed in triplicate.

2.5. Measurement of Melanin Content. B16F10 melanoma cells were placed in a 24 -well plate $\left(8 \times 10^{4}\right.$ cells/well $)$ in phenol-red-free media and incubated with CBR EtOAc fraction at $0,1,5$, and $10 \mu \mathrm{g} / \mathrm{mL}$ concentrations for 48 hours. The adherent B16F10 cells were washed with PBS and detached using 0.05\% Trypsin-EDTA. Cells were collected in a test tube and washed twice with PBS. The melanin was then extracted using a mixture of $1 \mathrm{~N} \mathrm{NaOH}$ : $10 \%$ DMSO at $80^{\circ} \mathrm{C}$ for $1 \mathrm{~h}$. After centrifugation at $3000 \mathrm{rpm}$ for $5 \mathrm{~min}$, the melanin content was determined at $475 \mathrm{~nm}$ using an ELISA microplate reader.

2.6. Western Blot Analysis. B16F10 melanoma cells were lysed in RIPA buffer (1\% Triton X-100, 100 mM Tris-HCl, pH 7.5, $10 \mathrm{mM} \mathrm{NaCl}, 10 \%$ glycerol, $1 \mathrm{mM}$ sodium orthovanadate, $50 \mathrm{mM}$ sodium fluoride, $1 \mathrm{mM}$-nitrophenyl phosphate, $1 \mathrm{mM}$ phenylmethylsulfonyl fluoride, and protease inhibitors, all from Sigma). Protein concentration was measured with the Bradford protein assay reagent (Bio-Rad), and equal amounts of proteins were applied to $12 \%$ SDS-PAGE gel. Proteins were transferred to nitrocellulose membrane (Millipore; Billerica, MA, USA) and blocked in 5\% nonfat milk for 1 hour. Samples were probed with the following primary antibodies: p53, microphthalmia-associated transcription factor (MITF), TRP-1, and $\beta$-actin (all from Santa Cruz, Santa Cruz, CA, USA). Secondary antibodies were horseradish peroxidase conjugated goat anti-rabbit or anti-mouse antibodies (Pierce, Rockford, IL, USA). Enhanced chemiluminescence reaction was performed using a SuperSignal West Femto enhancer kit (Pierce), and the positive bands were detected on X-ray film.

2.7. Tumor Growth Analysis In Vivo. The inhibitory effect of CBR EtOAc fraction on melanoma tumor growth was investigated in an animal model. C57BL/6 mice (6 weeks, female) were purchased from Dae-Han Experimental Animal Center (Eumsung, Korea). All animals were handled following the guidelines of the Institutional Animal Care and Use Committee (IACUC) at Konkuk University (Seoul, Republic of Korea). Tumors were induced on the skin as a melanoma mouse model as previously described [12]. Experiments were performed in four groups: normal control-saline injection; tumor control-B16F10 cell $\left(2 \times 10^{5}\right.$ cells/mouse $)$ injection intraperitoneally; CBR group-B16F10 and Changji (Antrodia camphorata) grown on germinated brown rice (CBR) EtOAc fraction injection by IP; Dox group-doxorubicin (Sigma) $1 \mathrm{mg} / \mathrm{kg} /$ day ( $n=7$ per group). In CBR and Dox groups, CBR EtOAc fraction $(100 \mathrm{mg} / \mathrm{kg} /$ day) and doxorubicin $(1 \mathrm{mg} / \mathrm{kg} /$ day) administration started three days before B16F10 melanoma cell transplantation until sacrifice. Body weight was measured every three days. Tumor was analyzed 
on day 15 following transplantation of B16F10 melanoma cells. Mice were sacrificed 15 days following cell inoculation, and morphology of tumor growth mass was imaged with digital camera (Power Shot A470; Canon, Tokyo, Japan), and tumor viscera were collected for histology and weight analysis.

2.8. HPLC Analysis. In order to analyze the compounds in the extracts, high performance liquid chromatography (HPLC) experiments were carried out on Agilent 1260 Infinity HPLC system (Santa Clara, CA) with the reversed phase column (Luna C18, $250 \times 4.6 \mathrm{~mm}, 5 \mu \mathrm{m}$ diameter, Phenomenex, Torrance, CA). The flow rate and injection volume were $1.2 \mathrm{~mL} / \mathrm{min}$ and $5-20 \mu \mathrm{L}$, respectively. The chromatograms were detected at $260 \mathrm{~nm}$ and collected at $30^{\circ} \mathrm{C}$. Adenosine was purchased from Sigma-Aldrich, St. Louis, MO, 99\%, and used as an authentic standard. One mg of adenosine was dissolved in $1 \mathrm{~mL}$ of $50 \%$ ethanol and filtrated using $0.45 \mu \mathrm{m}$ membrane filters. While the mobile phase for the ethanol extract of CBR was $8 \%$ aqueous methanol, that for other fractions separated based on the hydrophobicity was $6 \%$ aqueous methanol containing $0.1 \% \mathrm{KH} 2 \mathrm{PO} 4$.

2.9. Statistical Analysis. Data are expressed as means \pm standard error of the mean (SEM). Statistical analyses were performed using Student's $t$-test in Excel program (Microsoft, Redmond, WA, USA). Significant differences were considered from $P<0.05$.

\section{Results}

3.1. Antrodia camphorata Grown on Germinated Brown Rice (CBR) Fraction Inhibits B16F10 Melanoma Cell Proliferation. To determine the effect of Antrodia camphorata grown on germinated brown rice (CBR) fractions on B16F10 melanoma cell growth, we performed a cell proliferation assay as a screening tool for its anticancer activity. CBR hexane and $\mathrm{BuOH}$ fractions at $25 \mu \mathrm{g} / \mathrm{mL}$ inhibited B16F10 cell proliferation, with the CBR EtOAc being the most potent in antiproliferative activity (Figure 1(a)). Among the three fractions, the EtOAc fraction has the most efficient suppressive effect. Distilled water fractions had no effect on melanoma cell proliferation. Antiproliferative activity of CBR and AC (Antrodia camphorata) EtOAc fraction against B16F10 cells was compared. The $\mathrm{IC}_{50}$ of $\mathrm{CBR}$ EtOAc fraction $\left(\mathrm{IC}_{50}\right.$, $46.84 \pm 1.53 \mu \mathrm{g} / \mathrm{mL}$ ) was significantly lower than that of AC EtOAc fraction $\left(\mathrm{IC}_{50}, 60.20 \pm 3.27 \mu \mathrm{g} / \mathrm{mL}\right.$ ) (Figure 1(b)). This indicates that the inhibitory efficacy of CBR EtOAc fraction on melanoma cell proliferation is more effective than ordinary AC EtOAc fraction. Based on this data, we chose EtOAc fraction for further investigations of melanoma cell death. Figure 1(c) showed B16F10 melanoma cell proliferation in the presence of different EtOAc fraction concentrations ( 0 , $1,5,10$, and $25 \mu \mathrm{g} / \mathrm{mL})$. B16F10 melanoma cell proliferation displayed dose-dependent decrease after CBR treatment. The $\mathrm{IC}_{50}$ value of CBR EtOAc fraction against B16F10 cell proliferation was calculated as $19 \mu \mathrm{M}$ and $16 \mu \mathrm{M}$ at $48 \mathrm{~h}$ and $72 \mathrm{~h}$, respectively. These observations led to the selection of doses for further mechanistic and molecular studies that ranged from 1 to $20 \mu \mathrm{M}$. CBR EtOAc fraction did not affect normal cell (Raw264.7 mouse macrophage) proliferation at $25 \mu \mathrm{g} / \mathrm{mL}$ concentration.

3.2. CBR Induced Melanoma Cell Apoptosis. B16F10 cell death was further analyzed using annexin V-FITC/PI staining and flow cytometry (Figure 2). CBR EtOAc induced early (annexin $\mathrm{V} \mathrm{FITC} / \mathrm{PI}^{-}$) and late (annexin $\mathrm{V} \mathrm{FITC} / \mathrm{PI}^{+}$) apoptosis as shown in Figures 2(a) and 2(b). Data showed the dose-dependent increase in the numbers of apoptotic cells after $48 \mathrm{hr}$ treatment of CBR EtOAc fraction. In the control group, $8.58 \%$ (early apoptosis + late apoptosis) were positive for annexin V-FITC staining, while CBR EtOAc fraction treatment resulted in $12.05 \%, 17.68 \%$, and $19.13 \%$ at 1,5 , and $10 \mu \mathrm{g} / \mathrm{mL}$, respectively. The increased level of p53 protein expression was observed after 48 hour incubation with CBR EtOAc fraction. The p53 protein is a marker of apoptosis, known as an apoptosis initiation master switch $[13,14]$. This result indicates that the inhibition of melanoma cell proliferation by CBR occurs via p53-mediated apoptosis.

3.3. CBR EtOAc Fraction Induced Melanin Synthesis and the Expression of Melanogenesis Marker Molecules in B16F10 Cells. Melanogenesis occurs in differentiated melanoma cell. There is a report that the differentiated melanoma is associated with slower cell proliferation [15]. We studied how the CBR EtOAc fraction affected melanogenesis of B16F10 cells. As seen in Figure 3(a), CBR EtOAc fraction induced the melanin synthesis in a dose-dependent manner $(0,1,5$, and $10 \mu \mathrm{g} / \mathrm{mL})$. To demonstrate the detailed mechanism in melanin synthesis, the level of TRP-1 and MITF protein was investigated. MITF and TRP-1 have a crucial role in the survival and differentiation of melanoblasts and melanocytes $[16,17]$. After CBR EtOAc treatment, the levels of TRP-1 and MITF proteins were increased (Figure 3(b)), which indicated processed melanogenesis. Next, we checked whether CBR EtOAc fraction affected cellular morphology (Figure 3(c)). In control group, above $90 \%$ confluence of B16F10 melanoma cells was observed, and they still keep spindle-shape morphology after 48 hours. In contrast, CBR EtOAc fractiontreated group exhibited relatively less number of cells, and more dendritic-like shaped cells were observed, which is a morphological indicator for melanoma cell differentiation $[18,19]$.

3.4. CBR Inhibits Xenografted Melanoma Tumor Growth. To investigate whether CBR EtOAc fraction has an inhibitory effect on the tumor growth in mice, CBR was intraperitoneally administrated to mice with melanoma. We examined the suppressing effects of CBR EtOAc fraction on peritoneally disseminated melanoma tumor growth. At 15 days following melanoma cell grafting, peritoneal tumor nodules were counted and weighed. Body weights of mice were recorded every 3 days during the experiments and are displayed in Figure 4(a). CBR feeding appeared tolerable as depicted by similar body weight compared to control groups. However, mice receiving doxorubicin $(1 \mathrm{mg} / \mathrm{kg} /$ day) showed significant decrease $(12.31 \pm 1.68 \%)$ in body weights, compared to CBR 


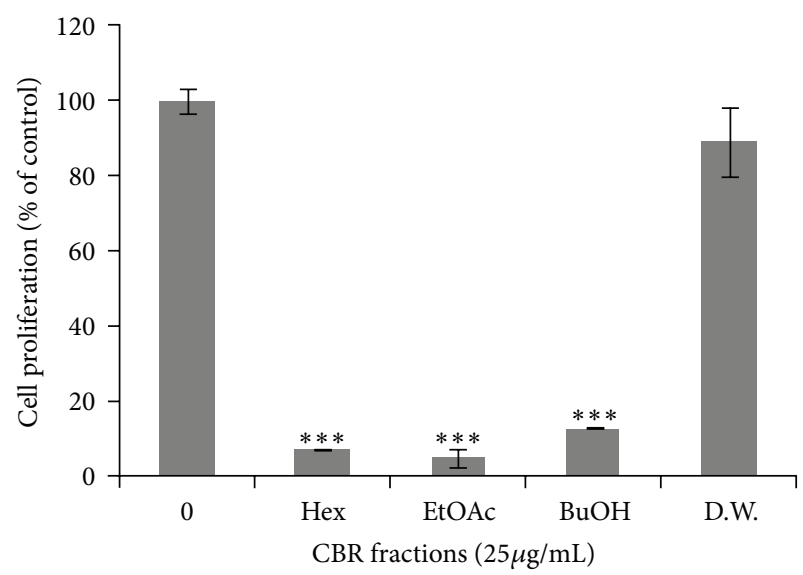

(a)

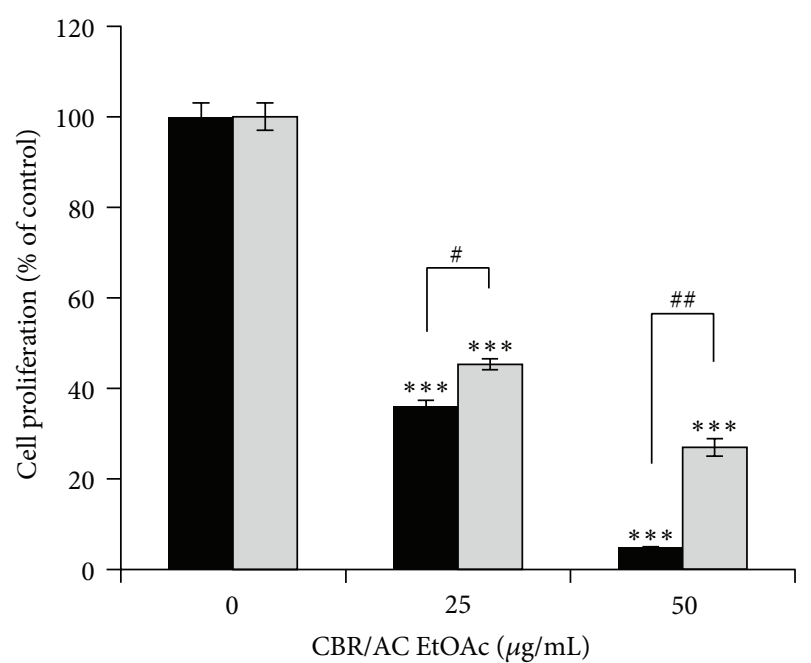

CBR

$\mathrm{AC}$

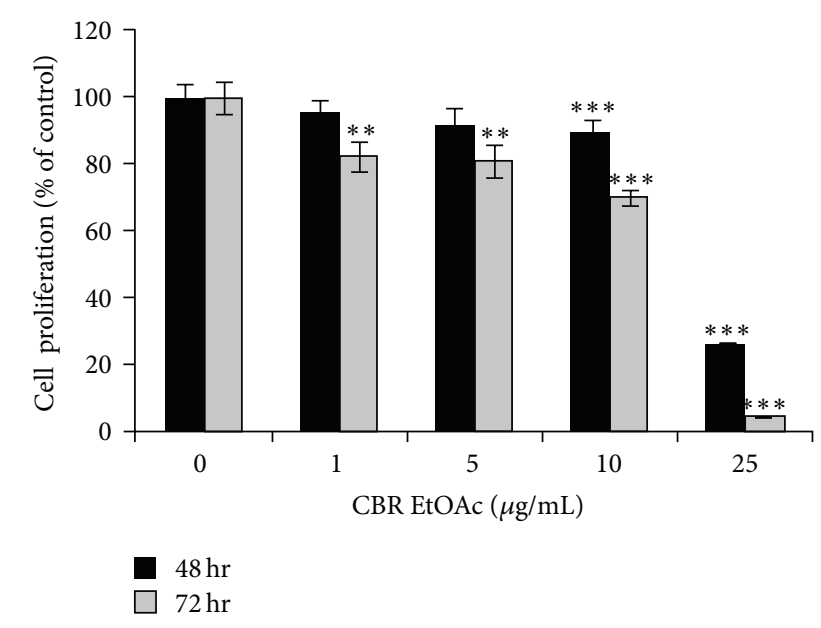

(b)

(c)

Figure 1: (a) B16F10 melanoma cell proliferation at 72 hours in the presence of each CBR fraction (hexane, EtOAc, BuOH, and water) compared to control. (b) Cell proliferation on CBR and AC EtOAc fraction $(0,25$, and $50 \mu \mathrm{g} / \mathrm{mL})$ for 48 hours $\left({ }^{\#} P<0.01\right.$, $\left.{ }^{\# \#} P<0.001\right)$. (c) B16F10 melanoma cells were treated with CBR EtOAc fraction at various concentrations $(0,1,5,10$, and $25 \mu \mathrm{g} / \mathrm{mL})$ for $48 \mathrm{hours}$. Cell viability was compared to control, and statistically different level was denoted by ${ }^{*} P<0.05,{ }^{* *} P<0.01,{ }^{* * *} P<0.001$.

EtOAc fraction-treated or control group $(P<0.05)$. At day 15 th, melanoma was widely disseminated on whole intestine. In contrast, the peritoneally disseminated tumor mass growth was significantly inhibited in mice given CBR EtOAc fraction $(100 \mathrm{mg} / \mathrm{kg} /$ day) (Figure $4(\mathrm{~b})$ ). In the tumor control group, mean of tumor weight amounted to $2.84 \pm 0.45 \mathrm{~g}$, whereas the mean of tumor burden in CBR EtOAc fraction-treated group was only $0.84 \pm 0.30 \mathrm{~g}$, representing a significant suppression in tumor growth by $29 \%$ (Figure $4(\mathrm{c})$ ).

3.5. Chromatogram of Adenosine on $C B R$ and $A C$. In the HPLC experimental condition for the fractions separated based on the hydrophobicity, the authentic adenosine was observed at the retention time of $22 \mathrm{~min}$ in its chromatogram as $99 \%$. Among the samples, adenosine was observed from
CBR EtOAc fraction, and its concentration was 0.0196\% (Figure 5), and it was not detected on AC extract and other $\mathrm{CBR}$ fractions (Hex, $\mathrm{BuOH}$, and water).

\section{Discussion}

Melanoma is the most serious type of skin diseases with many obstacles in traditional cancer therapy (e.g., resistance to current method and fast metastatic property). Therefore, establishing more effective and safe treatment regimen is in need. In this study, we investigated Changji mushroom (Antrodia camphorata) grown on germinated brown rice (CBR), as a novel and efficient antimelanoma agent. Antrodia camphorata $(\mathrm{AC})$ is a well-known medicinal mushroom that 
CBR EtOAc fraction $(\mu \mathrm{g} / \mathrm{mL})$

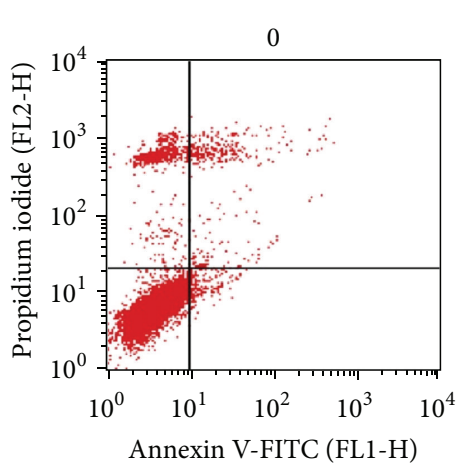

Annexin V-FITC (FL1-H)

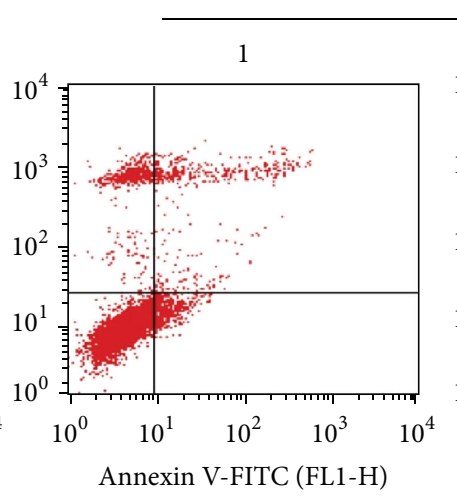

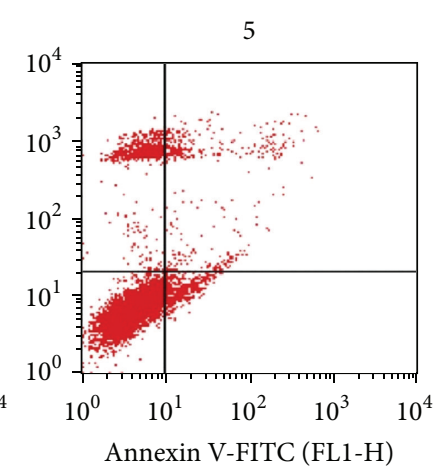

10

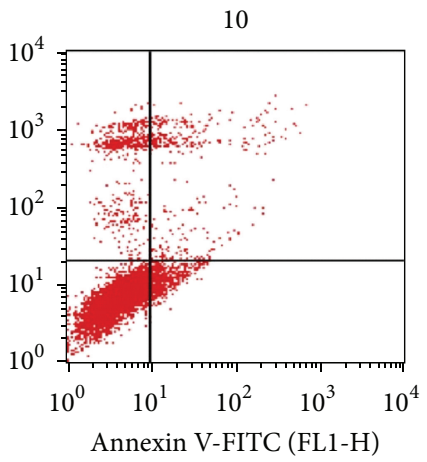

(a)

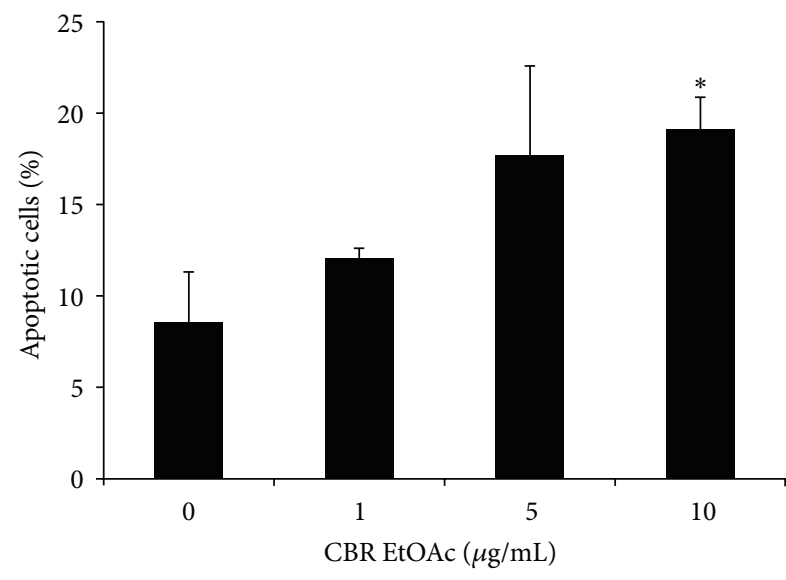

(b)

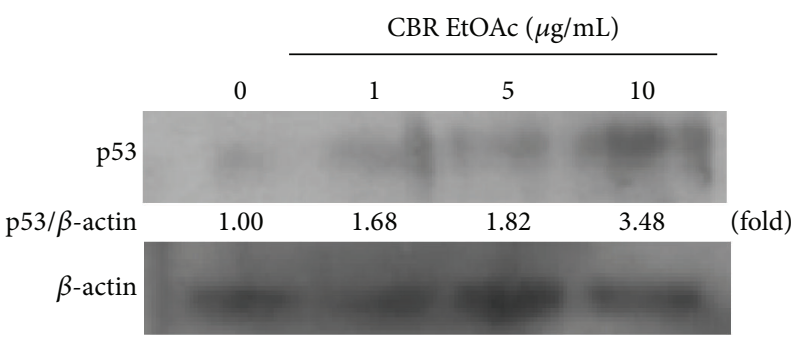

(c)

Figure 2: (a) Annexin V-FITC/PI staining analysis for apoptosis. Cells were treated with 1, 5, and $10 \mu \mathrm{g} / \mathrm{mL}$ CBR EtOAc fraction for 48 hours. After treatment, the cells were stained with Annexin V-FITC/PI and subjected to flow cytometry analysis. (b) The quantitive result of apoptotic cells. Significant difference compared to the control is denoted by ${ }^{*} P<0.05$. (c) p53 expression by western blotting on $0,1,5$, and $10 \mu \mathrm{g} / \mathrm{mL}$ CBR EtOAc treatment.

has been used in oriental medicine for treating various diseases. Previous studies have demonstrated that AC has a wide range of pharmacological activities, including anticancer properties [7-11]. Specifically, AC induces apoptotic cell death in human leukemia [20], breast [9], ovarian [11], colon, [21] and liver cancer cells [10]. However, apoptotic effect of AC on melanoma cells has never been studied. In the present study, the inhibitory effect of $\mathrm{AC}$ on germinated brown rice (CBR) and on melanoma cell growth was investigated including the induction of apoptotic cell death and melanogenesis as well as the suppressive effect on melanoma growth with the xenografted mice.

Cancer cells generally show uncontrolled/high proliferation, migration, and matrix-invasion potentials [22]. They lost the regulation of cell-cycle checkpoints or were resistant to the programmed cell death (apoptosis). Therefore, inhibition of tumor growth is the most attractive approach in developing anticancer agents. In Figure 1, B16F10 cell proliferation was significantly inhibited in the order of CBR-EtOAc fraction > CBR-BuOH fraction > CBR-hexane fraction. Therefore, CBR EtOAc fraction was chosen for further studies.

Figure 2 results elucidated that the CBR EtOAc treatment increased p53-mediated apoptotic cell death. Apoptosis is a programmed cell death via the intricate pathways and is known to be deeply associated with the early stage of skin carcinogenesis [23]. Annexin V-FITC/PI staining was performed to confirm the apoptotic cell population increase with CBR EtOAc fraction treatment (Figures 2(a) and 2(b)). p53 protein is a transcription factor that being profoundly involved in apoptosis and used as a tumor suppressor was investigated $[13,24]$. Increased level of p53 proteins under CBR EtOAc treatment demonstrated that p53 had a major role in apoptotic B16F10 melanoma cell death (Figure 2(c)). Similarly, Tokgun et al. reported that medicinal plants of Convolvulus galaticus, Crocus antalyensis, and Lilium candidum extracts showed cytotoxic effect on human breast cancer cells by p53-mediated apoptosis [25]. It seems that CBR EtOAc fraction exerts its antitumor activity through inducing the cellular apoptotic response. 


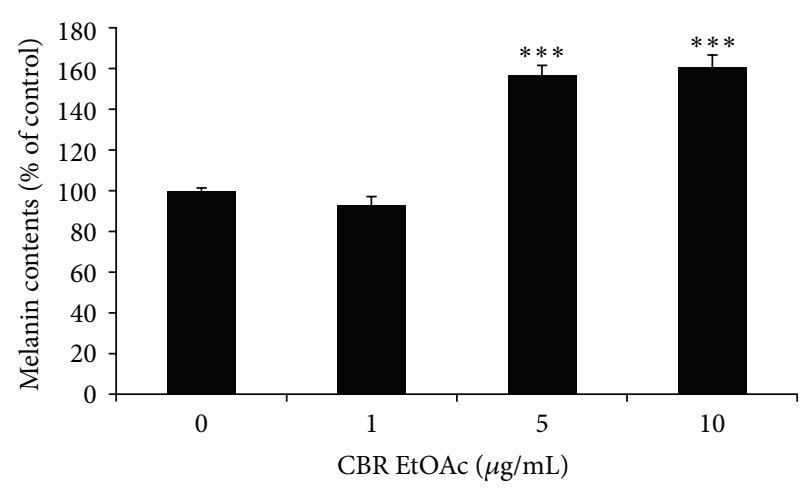

(a)

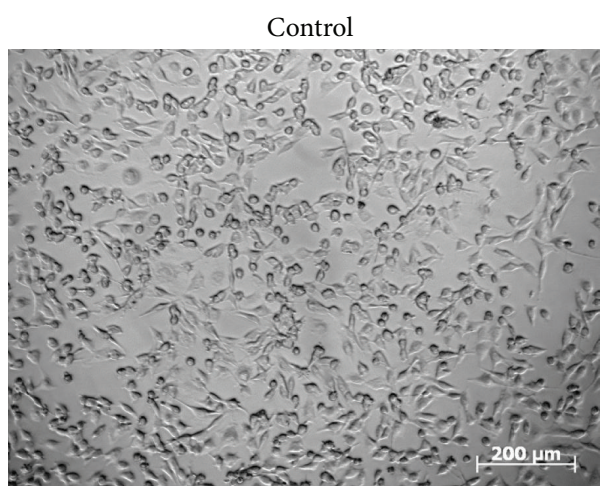

CBR EtOAc $5 \mu \mathrm{g} / \mathrm{mL}$

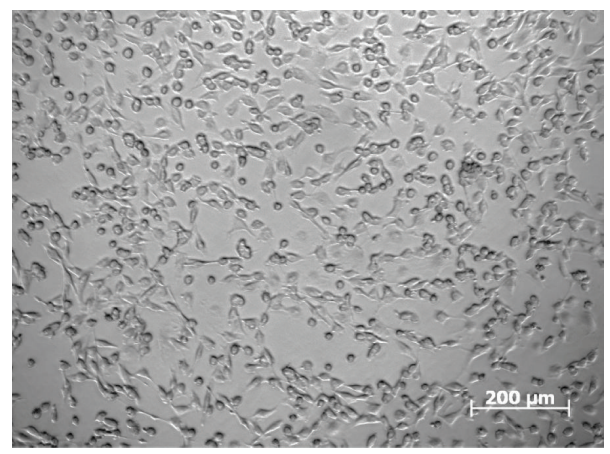

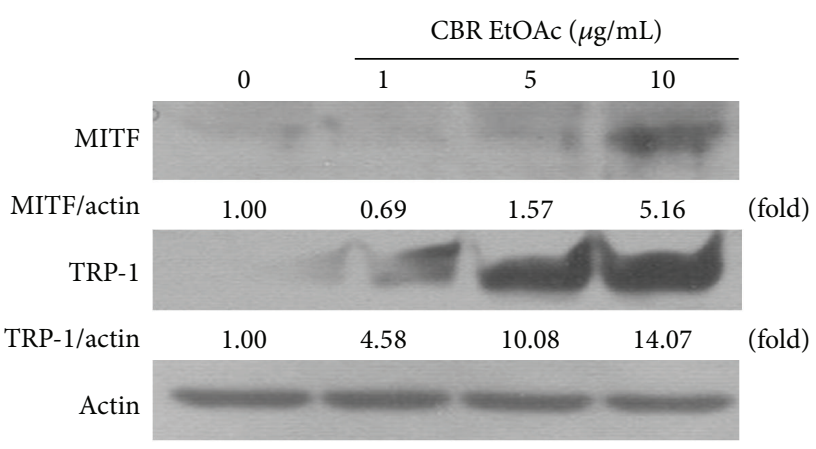

(b)

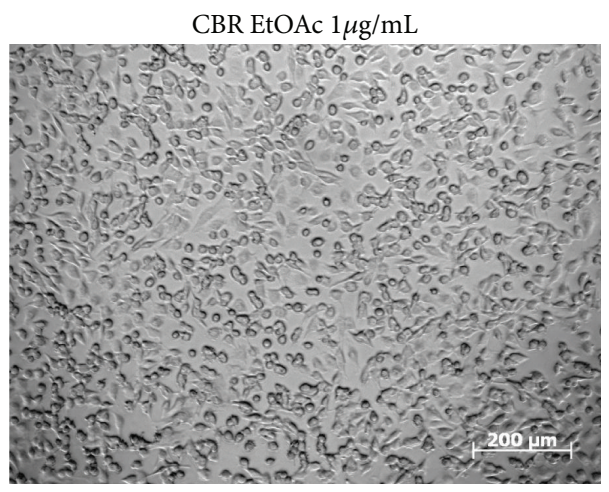

CBR EtOAc $10 \mu \mathrm{g} / \mathrm{mL}$

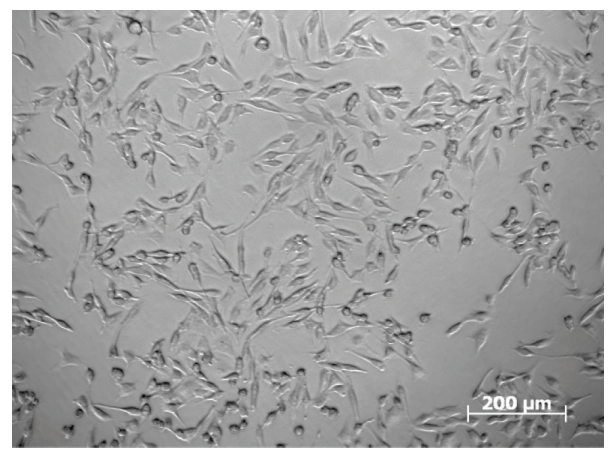

(c)

Figure 3: (a) Melanin production in B16F10 melanoma cells upon CBR EtOAc treatment $(0,1,5$, and $10 \mu \mathrm{g} / \mathrm{mL})$ for 48 hours. The melanin content was measured with a microplate reader at $475 \mathrm{~nm}$. All experiments are performed in triplicate $\left({ }^{* * *} P<0.001\right)$. (b) Representative western blot images of MITF, TRP-1, and $\beta$-actin under EtOAc fraction treatment $(0,1,5$, and $10 \mu \mathrm{g} / \mathrm{mL})$. (c) Phase contrast microscopy: representative images of B16F10 melanoma cells treated with $0,1,5$, and $10 \mu \mathrm{g} / \mathrm{mL} \mathrm{CBR} \mathrm{EtOAc} \mathrm{and} \mathrm{controls} \mathrm{for} 48$ hours (scale bar $=200 \mu \mathrm{m}$ ).

We also tested whether the CBR EtOAc fraction induced melanogenesis based on the recent report that the differentiated melanoma was associated with slower cell proliferation [15]. As seen in Figure 3, CBR EtOAc treatment significantly increased melanin production and MITF and TRP-lexpression, which are melanogenesis-related proteins. Melanin synthesis occurs in the melanosome. MITF was a master regulator of its core component, and its upregulated protein expression resulted in cellular differentiation $[16,26]$. TRP-1 is also an important melanosome core component [17]. Based upon these results, the suppressive effect of CBR EtOAc fraction against B16F10 melanoma cell proliferation can be explained as an increased apoptosis and an induced melanogenesis.

In addition, the anticancer effect of CBR EtOAc fraction was confirmed in melanoma-xenografted animal model. Other previous studies that showed AC against colon or breast cancer demonstrated its anticancer activity only in the cellular level [7-9]. However, in vivo efficacy testing is a critical step for clinical application. We used $100 \mathrm{mg} / \mathrm{kg}$ of CBR EtOAc fraction, and significant melanoma growth suppression was observed compared to control (Figure 4). This $\mathrm{CBR}$ concentration is relatively low concentration compared to other studies. For example, when the anticancer activity 


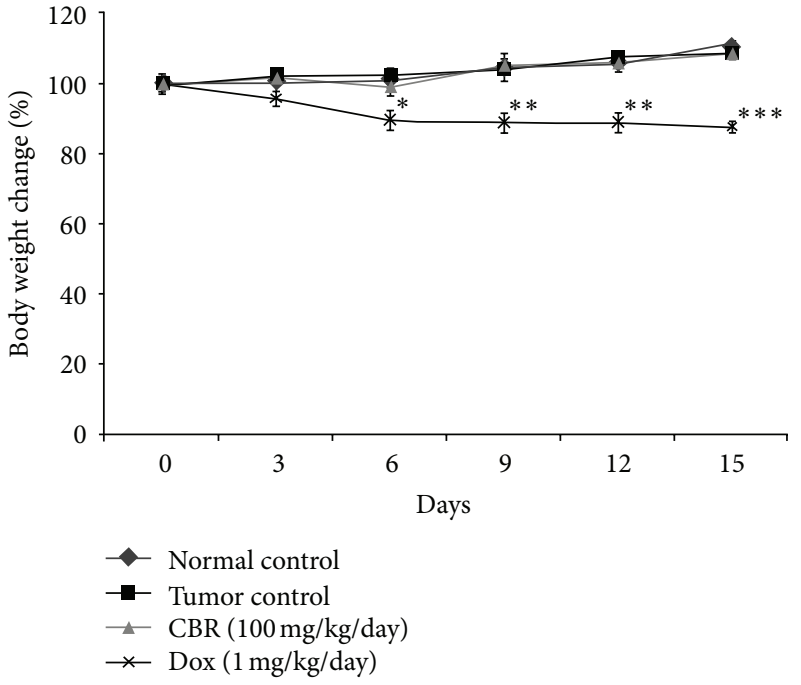

(a)

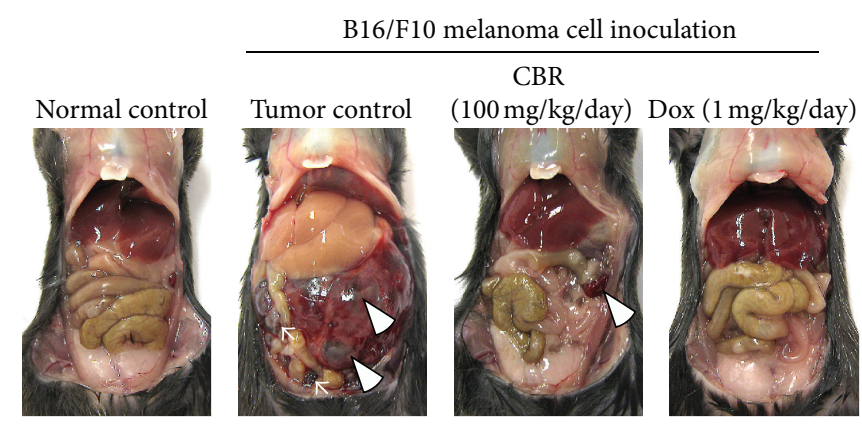

(b)

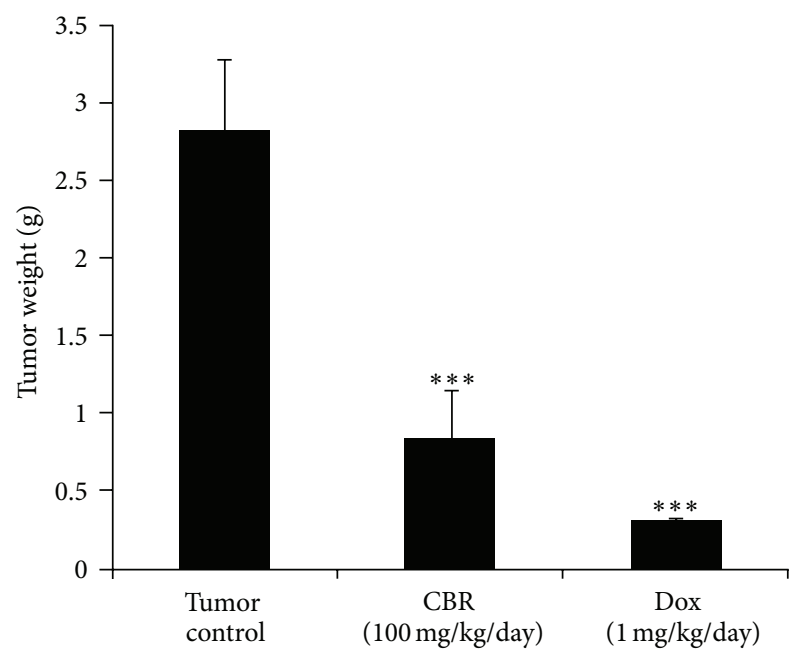

(c)

FIGURE 4: Effect of CBR EtOAc fraction on tumor growth in melanoma cell xenografted mice. (a) Average body weight of control and CBR, Dox-treated mice plotted over days after tumor cell inoculation: points: mean of seven animals. (b) Tumor nodule (arrow) and viscera mass (arrow head) of B16F10-inoculated mice treated with CBR (100 mg/kg/day) and Dox (1 mg/kg/day). (c) Tumor weight changes in B16F10inoculated mice treated with CBR $(100 \mathrm{mg} / \mathrm{kg} / \mathrm{day})$ and Dox $(1 \mathrm{mg} / \mathrm{kg} / \mathrm{day})$ and controls $\left({ }^{*} P<0.05,{ }^{* *} P<0.01,{ }^{* * *} P<0.001\right)$.

of resveratrol was tested in vivo, dose of $40-1,500 \mathrm{mg} / \mathrm{kg}$ (RES/mice body weight) was applied [5, 27]. Using dose scaling as advised in FDA guidance, the human equivalent dose of CBR EtOAc fraction in our in vivo study can be applied to approximately $427.26 \mathrm{mg}$ of CBR and to a $60 \mathrm{~kg}$ adult and represents a reasonable starting point for future clinical investigations.

As seen in Figure 1, CBR EtOAc fraction showed more potent antimelanoma cell proliferative activity compared to AC EtOAc fraction and other CBR fractions. The active components of each CBR EtOAc fraction were analyzed by HPLC analysis, and only CBR EtOAc fraction contained adenosine. Adenosine showed an antitumor effect and was used as a potent regulator of normal and tumor cell growth $[28,29]$. Recently, Madi et al. reported that adenosine increased melanin level by activating adenosine receptors [30].

\section{Conclusion}

Current study demonstrated that CBR EtOAc fraction inhibited melanoma cell proliferation through the induction of subsequent apoptosis and melanogenesis. Importantly, in vitro study result was reflected in our in vivo studies that showed significant melanoma growth inhibition in mice implanted with melanoma xenografts upon treatment with CBR EtOAc fraction. Adenosine was investigated as an active component from CBR EtOAc fraction. Further work will be focused on isolating active components in CBR EtOAc 

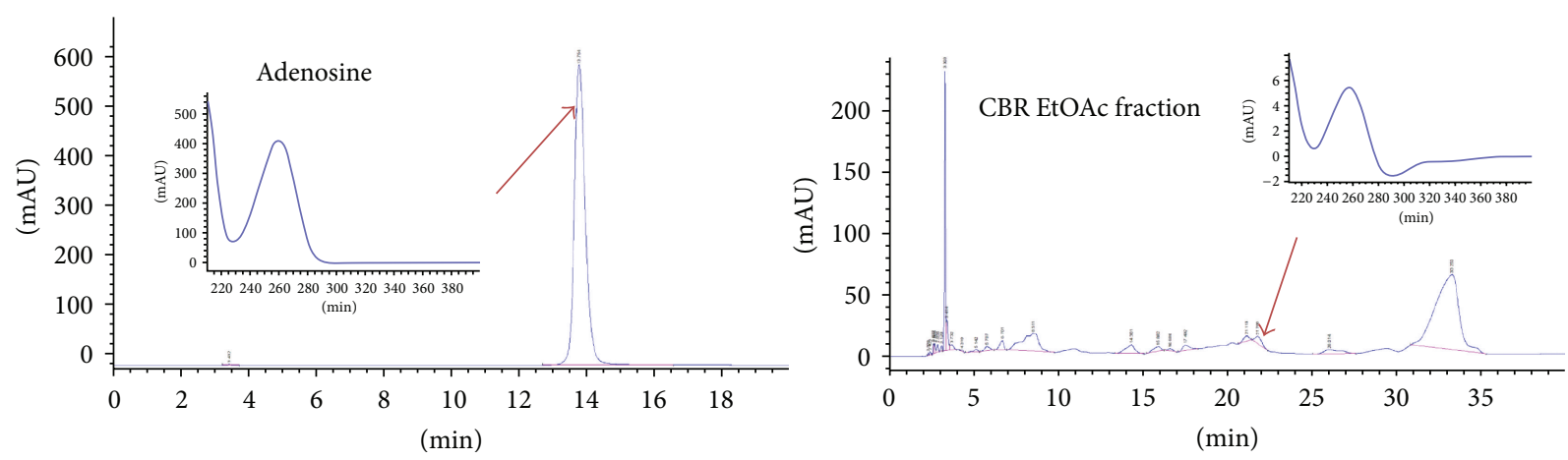

(a)

\begin{tabular}{cccccc}
\hline \multirow{2}{*}{$\begin{array}{c}\text { Standard } \\
\text { adenosine }\end{array}$} & \multicolumn{4}{c}{ CBR } & AC \\
\cline { 2 - 6 } & Hex & EA & BuOH & Water & EA \\
\hline $99 \%$ & N/A & $0.0196 \%$ & N/A & N/A & N/A \\
\hline
\end{tabular}

(b)

FIGURE 5: Representative high-performance liquid chromatography characterization of the components with detection at $230 \mathrm{~nm}$ showing adenosine (arrow) in adenosine standard and CBR extract.

extract that contribute to its anticancer activity. In future applications, this study gives the strong evidence that CBR extract may be a strong candidate in novel cancer prevention and therapeutic strategies.

\section{Conflict of Interests}

The authors declare that they have no conflict of interests.

\section{Authors' Contribution}

M. Song and D. K. Park equally contributed to this paper.

\section{Acknowledgments}

This work was supported by the SMART Research Professor Program of Konkuk University, Seoul, Republic of Korea. The authors also thank Ms. Jung Won Choi and Sun mi Kim for technical support.

\section{References}

[1] D. Yach, D. Stuckler, and K. D. Brownell, "Epidemiologic and economic consequences of the global epidemics of obesity and diabetes," Nature Medicine, vol. 12, no. 1, pp. 62-66, 2006.

[2] A. H. Mokdad, B. A. Bowman, E. S. Ford, F. Vinicor, J. S. Marks, and J. P. Koplan, "The continuing epidemics of obesity and diabetes in the United States," Journal of the American Medical Association, vol. 286, no. 10, pp. 1195-1200, 2001.

[3] D. Naishadham and A. Jemal, "Cancer statistics, 2012," CA Cancer Journal for Clinicians, vol. 62, no. 1, pp. 10-29, 2012.

[4] D. N. Syed, F. Afaq, N. Maddodi et al., "Inhibition of human melanoma cell growth by the dietary flavonoid fisetin is associated with disruption of $\mathrm{Wnt} / \beta$-catenin signaling and decreased mitf levels," Journal of Investigative Dermatology, vol. 131, no. 6, pp. 1291-1299, 2011.

[5] G. Gatouillat, E. Balasse, D. Joseph-Pietras, H. Morjani, and C. Madoulet, "Resveratrol induces cell-cycle disruption and apoptosis in chemoresistant B16 melanoma," Journal of Cellular Biochemistry, vol. 110, no. 4, pp. 893-902, 2010.

[6] D. N. Syed and H. Mukhtar, "Botanicals for the prevention and treatment of cutaneous melanoma," Pigment Cell and Melanoma Research, vol. 24, no. 4, pp. 688-702, 2011.

[7] L. Y. Chen, M. T. Sheu, D. Z. Liu et al., "Pretreatment with an ethanolic extract of Taiwanofungus camphoratus (Antrodia camphorata) enhances the cytotoxic effects of amphotericin B," Journal of Agricultural and Food Chemistry, vol. 59, no. 20, pp. 11255-11263, 2011.

[8] S. H. Tu, C. H. Wu, L. C. Chen et al., "In vivo antitumor effects of 4, 7-Dimethoxy-5-methyl-1, 3-benzodioxole isolated from the fruiting body of Antrodia camphorata through activation of the p53-Mediated p27/Kip1 signaling pathway," Journal of Agricultural and Food Chemistry, vol. 60, no. 14, pp. 3612-3618, 2012.

[9] W.-L. Lin, Y.-J. Lee, P.-Y. Huang, and T.-H. Tseng, "Inhibition of cell survival, cell cycle progression, tumor growth and cyclooxygenase-2 activity in MDA-MB-231 breast cancer cells by camphorataimide B," European Journal of Pharmacology, vol. 680, no. 1-3, pp. 8-15, 2012.

[10] Y. K. Rao, J. Whang-Peng, C.-Y. F. Huang, S.-K. Shyue, S.L. Hsu, and Y.-M. Tzeng, "Antcin B and its ester derivative from Antrodia camphorata induce apoptosis in hepatocellular carcinoma cells involves enhancing oxidative stress coincident with activation of intrinsic and extrinsic apoptotic pathway," Journal of Agricultural and Food Chemistry, vol. 59, no. 20, pp. 10943-10954, 2011.

[11] F.-S. Liu, P.-Y. Yang, D.-N. Hu, Y.-W. Huang, and M.-J. Chen, "Antrodia camphorata induces apoptosis and enhances the cytotoxic effect of paclitaxel in human ovarian cancer cells," 
International Journal of Gynecological Cancer, vol. 21, no. 7, pp. 1172-1179, 2011.

[12] E. S. Han, J. Y. Oh, and H. J. Park, "Cordyceps militaris extract suppresses dextran sodium sulfate-induced acute colitis in mice and production of inflammatory mediators from macrophages and mast cells," Journal of Ethnopharmacology, vol. 134, no. 3, pp. 703-710, 2011.

[13] S. Haupt, M. Berger, Z. Goldberg, and Y. Haupt, "Apoptosis: the p53 network," Journal of Cell Science, vol. 116, no. 20, pp. 40774085, 2003.

[14] A. J. Levine, "p53, the cellular gatekeeper for growth and division,” Cell, vol. 88, no. 3, pp. 323-331, 1997.

[15] N. Puri, M. S. Eller, H. R. Byers, S. Dykstra, J. Kubera, and B. A. Gilchrest, "Telomere-based DNA damage responses: a new approach to melanoma," FASEB Journal, vol. 18, no. 12, pp.13731381, 2004.

[16] R. E. Bell and C. Levy, “The three M's: melanoma, microphthalmia-associated transcription factor and microRNA," Pigment Cell Melanoma Resesearch, vol. 24, no. 6, pp. 1088-1106, 2011.

[17] Z. Abdel-Malek, V. B. Swope, I. Suzuki et al., "Mitogenic and melanogenic stimulation of normal human melanocytes by melanotropic peptides," Proceedings of the National Academy of Sciences of the United States of America, vol. 92, no. 5, pp. 17891793, 1995.

[18] A. Serafino, P. Sinibaldi-Vallebona, G. Lazzarino et al., "Differentiation of human melanoma cells induced by cyanidin-3-O$\beta$ - glucopyranoside," FASEB Journal, vol. 18, no. 15, pp. 19401942, 2004.

[19] A. Gismondi, A. Lentini, C. Tabolacci, B. Provenzano, and S. Beninati, "Transglutaminase-dependent antiproliferative and differentiative properties of nimesulide on B16-F10 mouse melanoma cells," Amino Acids, vol. 38, no. 1, pp. 257-262, 2010.

[20] Y. C. Hseu, H. L. Yang, Y. C. Lai, J. G. Lin, G. W. Chen, and Y. H. Chang, "Induction of apoptosis by Antrodia camphorata in human premyelocytic leukemia HL-60 cells," Nutrition and Cancer, vol. 48, no. 2, pp. 189-197, 2004.

[21] H. M. Lien, H. W. Lin, Y. J. Wang et al., "Inhibition of anchorageindependent proliferation and G0/G1 cell-cycle regulation in human colorectal carcinoma cells by 4, 7-Dimethoxy-5-Methyl1, 3-Benzodioxole isolated from the fruiting body of Antrodia camphorate," Evidence-Based Complementary and Alternative Medicine, vol. 2011, Article ID 984027, 10 pages, 2011.

[22] C. J. Sherr, "Principles of tumor suppression," Cell, vol. 116, no. 2, pp. 235-246, 2004.

[23] P. F. Robbins, R. A. Morgan, S. A. Feldman et al., "Tumor regression in patients with metastatic synovial cell sarcoma and melanoma using genetically engineered lymphocytes reactive with NY-ESO-1," Journal of Clinical Oncology, vol. 29, no. 7, pp. 917-924, 2011.

[24] R. Vogt Sionov and Y. Haupt, "The cellular response to p53: the decision between life and death," Oncogene, vol. 18, no. 45, pp. 6145-6157, 1999.

[25] O. Tokgun, H. Akca, R. Mammadov, C. Aykurt, and G. Deniz, "Convolvulus galaticus, Crocus antalyensis, and Lilium candidum extracts show their antitumor activity through induction of p53-mediated apoptosis on human breast cancer cell line MCF-7 cells," Journal of Medicinal Food, vol. 15, no. 11, pp. 1000 1005, 2012.

[26] S. Carreira, J. Goodall, I. Aksan et al., "Mitf cooperates with $\mathrm{Rb} 1$ and activates p21Cipl expression to regulate cell cycle progression," Nature, vol. 433, no. 7027, pp. 764-769, 2005.
[27] H. B. Zhou, J. J. Chen, W. X. Wang, J. T. Cai, and Q. Du, "Anticancer activity of resveratrol on implanted human primary gastric carcinoma cells in nude mice," World Journal of Gastroenterology, vol. 11, no. 2, pp. 280-284, 2005.

[28] S. Merighi, P. Mirandola, K. Varani et al., "A glance at adenosine receptors: novel target for antitumor therapy," Pharmacology and Therapeutics, vol. 100, no. 1, pp. 31-48, 2003.

[29] K. Nakamura, N. Yoshikawa, Y. Yamaguchi, S. Kagota, K. Shinozuka, and M. Kunitomo, "Antitumor effect of cordycepin ( $3^{\prime}$-deoxyadenosine) on mouse melanoma and lung carcinoma cells involves adenosine A3 receptor stimulation," Anticancer Research, vol. 26, no. 1 A, pp. 43-47, 2006.

[30] L. Madi, B. Rosenberg-Haggen, A. Nyska, and R. Korenstein, "Enhancing pigmentation via activation of A3 adenosine receptors in B16 melanoma cells and in human skin explants," Experimental Dermatology, vol. 22, no. 1, pp. 74-77, 2013. 


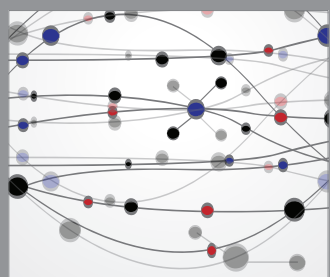

The Scientific World Journal
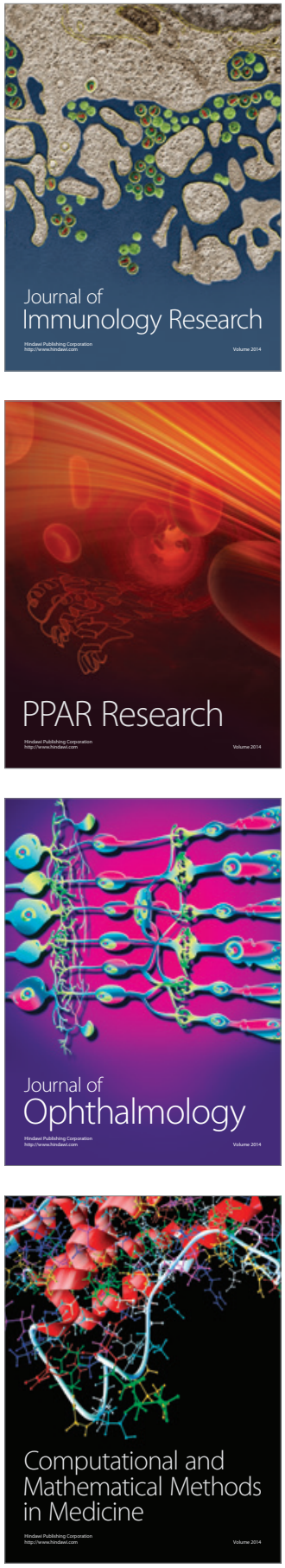

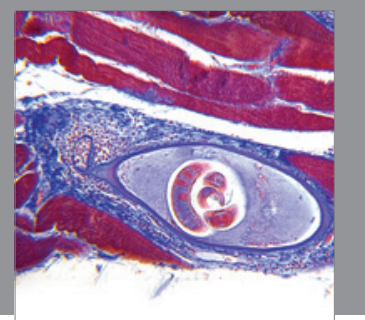

Gastroenterology

Research and Practice
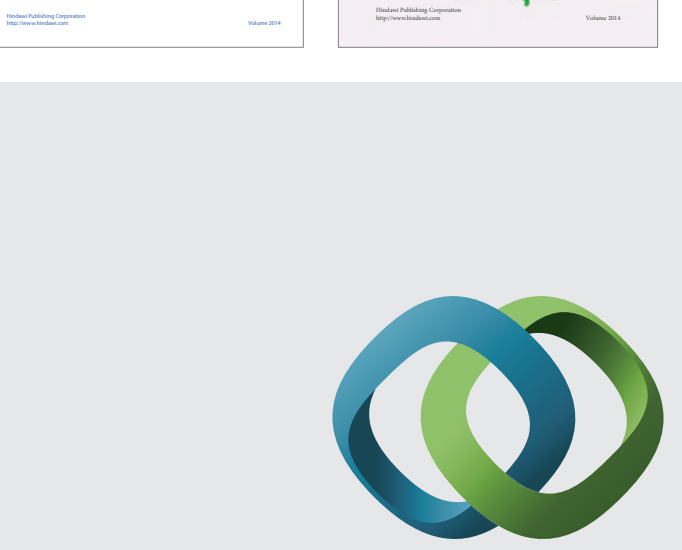

\section{Hindawi}

Submit your manuscripts at

http://www.hindawi.com
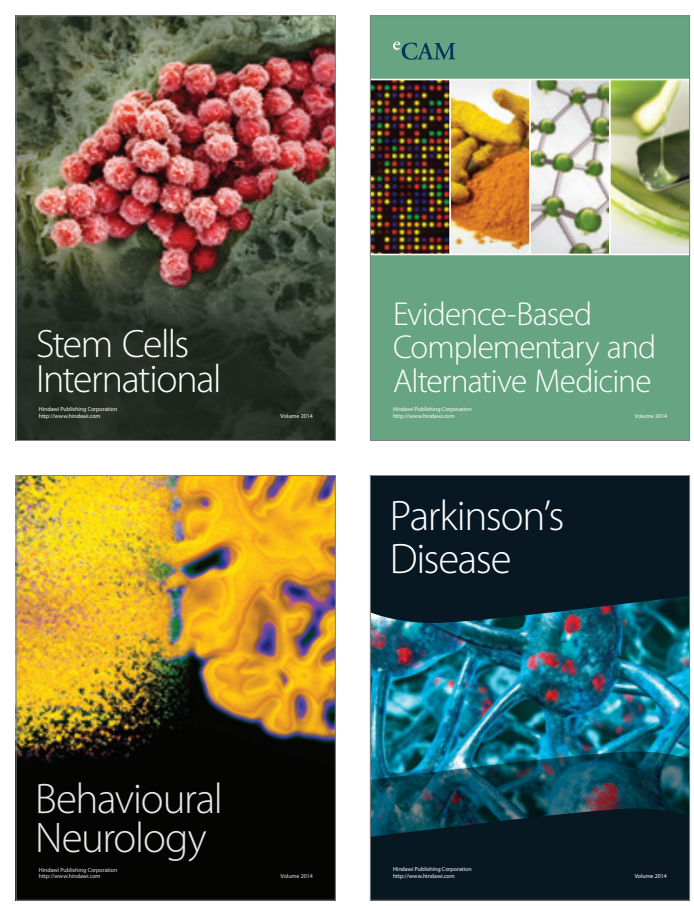

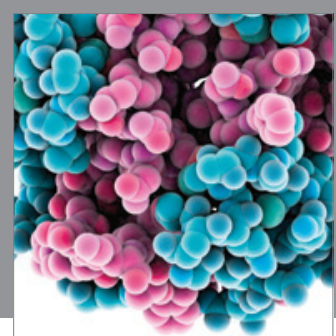

Journal of
Diabetes Research

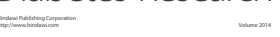

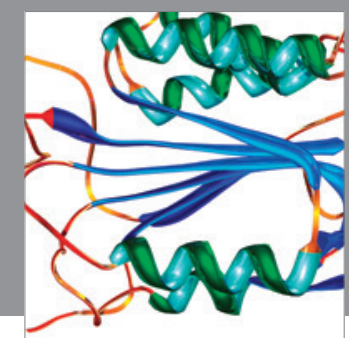

Disease Markers
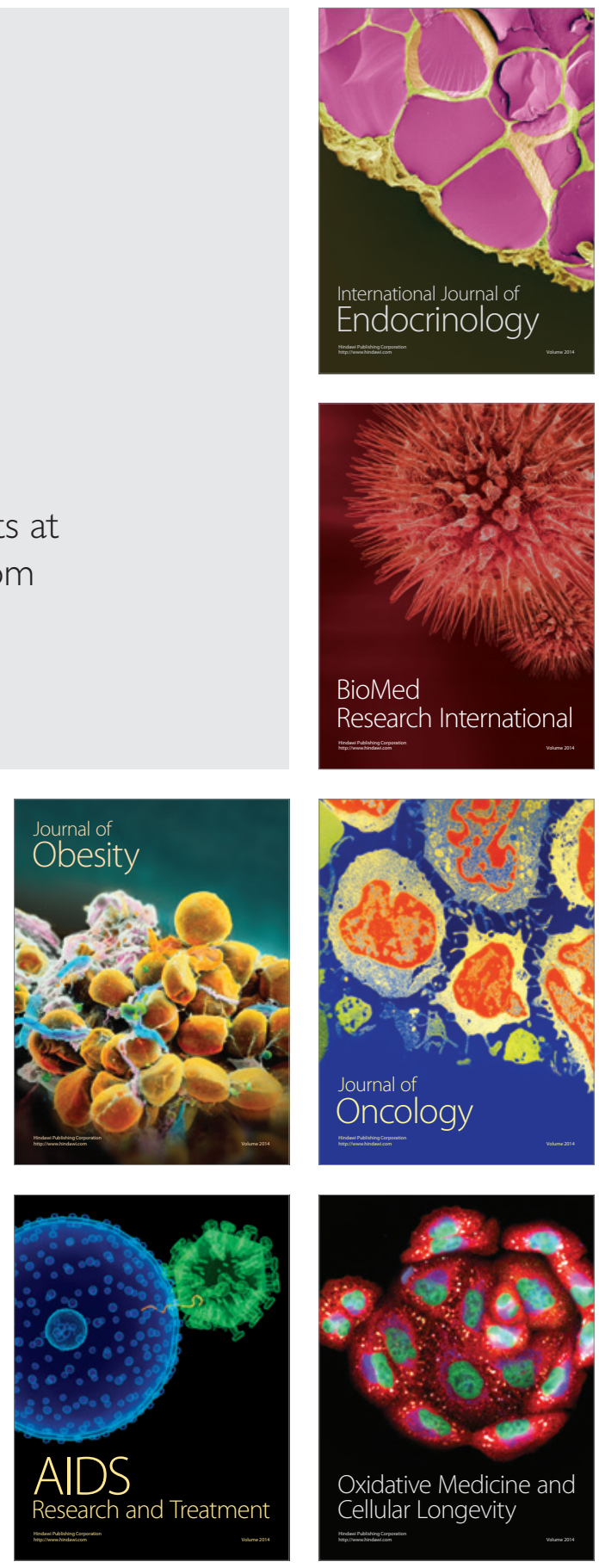